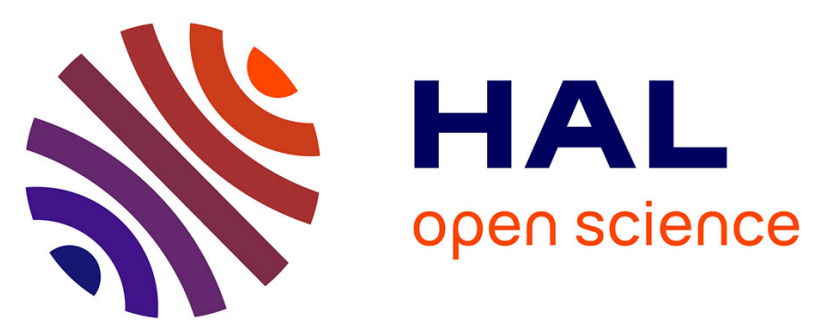

\title{
Quantitative geometric analysis of rib, costal cartilage and sternum from childhood to teenagehood
}

Baptiste Sandoz, Alina Badina, Sébastien Laporte, Karene Lambot, David Mitton, Wafa Skalli

\section{- To cite this version:}

Baptiste Sandoz, Alina Badina, Sébastien Laporte, Karene Lambot, David Mitton, et al.. Quantitative geometric analysis of rib, costal cartilage and sternum from childhood to teenagehood. Medical and Biological Engineering and Computing, 2013, 51 (9), pp.971-979. 10.1007/s11517-013-1070-5 . hal01020521

\section{HAL Id: hal-01020521 https://hal.science/hal-01020521}

Submitted on 8 Jul 2014

HAL is a multi-disciplinary open access archive for the deposit and dissemination of scientific research documents, whether they are published or not. The documents may come from teaching and research institutions in France or abroad, or from public or private research centers.
L'archive ouverte pluridisciplinaire HAL, est destinée au dépôt et à la diffusion de documents scientifiques de niveau recherche, publiés ou non, émanant des établissements d'enseignement et de recherche français ou étrangers, des laboratoires publics ou privés. 


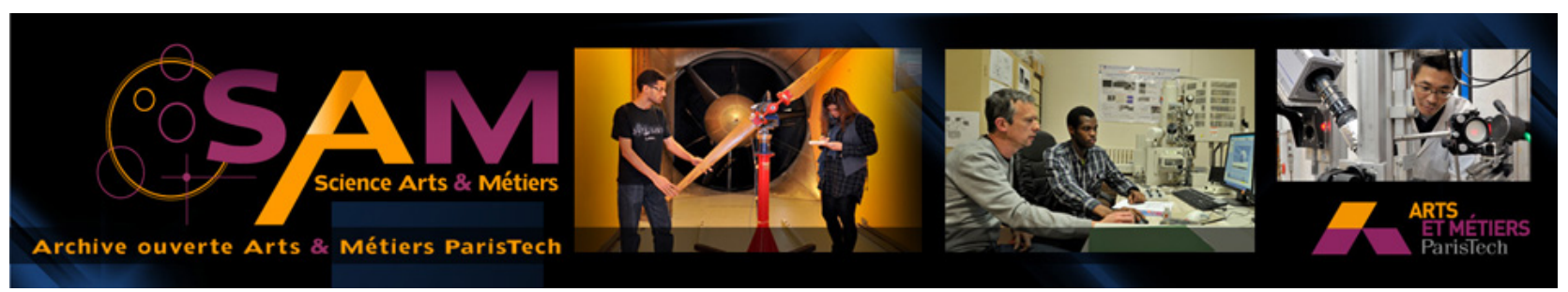

\section{Science Arts \& Métiers (SAM)}

is an open access repository that collects the work of Arts et Métiers ParisTech researchers and makes it freely available over the web where possible.

This is an author-deposited version published in: http://sam.ensam.eu

Handle ID: .http://hdl.handle.net/10985/8327

\section{To cite this version :}

Baptiste SANDOZ, Alina BADINA, Sébastien LAPORTE, Karene LAMBOT, David MITTON, Wafa SKALLI - Quantitative geometric analysis of rib, costal cartilage and sternum from childhood to teenagehood - Medical and biological enginnering and computing - Vol. 51, n`9, p.971-979- 2013 


\section{Quantitative geometric analysis of rib, costal}

7 cartilage and sternum from childhood to

\section{8 teenagehood}

9 Baptiste Sandoz ${ }^{1}$, Alina Badina ${ }^{2}$, Sébastien Laporte ${ }^{1}$, Karene Lambot ${ }^{3}$,

10 David Mitton ${ }^{1}$, Wafa Skalli ${ }^{1}$

$13{ }^{1}$ Arts et Metiers ParisTech, LBM, 151 bd de l'Hopital 75013 Paris, France

$14{ }^{2}$ Université Paris Descartes, Faculté de Médecine, Hôpital Necker, Service

15 d'orthopédie pédiatrique, 149 rue de Sèvre, 75015, Paris, France

$16{ }^{3}$ Université Paris Descartes, Faculté de Médecine, Hôpital Necker, Service de

17 radiologie pédiatrique, 149 rue de Sèvre, 75015, Paris, France

Corresponding author:

21 Dr Baptiste Sandoz

22 baptiste.sandoz@ensam.eu

23 Arts et Metiers ParisTech, LBM, 151 boulevard de l'hopital, 75013 Paris, France

24 Tel: +33144246364

25 Fax: +33144246366

26

27

Total word count: 3699

Abstract word count: 193

31 Number of Tables: 1

32 Complementary material: 1

33

34 


\section{Abstract}

36 Better understanding of the effects of growth on children's bones and cartilage is necessary for

37 clinical and biomechanical purposes. The aim of this study is to define the $3 \mathrm{D}$ geometry of

38 children's rib cages: including sternum, ribs and costal cartilage. Three-dimensional

39 reconstructions of 960 ribs, 518 costal cartilages and 113 sternebrae were performed on thoracic

40 CT-scans of 48 children, aged four months to 15 years. The geometry of the sternum was detailed

41 and nine parameters were used to describe the ribs and rib cages. A "costal index" was defined as

42 the ratio between cartilage length and whole rib length to evaluate the cartilage ratio for each rib

43 level. For all children, the costal index decreased from rib level one to three and increased from

44 level three to seven. For all levels, the cartilage accounted for 45 to $60 \%$ of the rib length, and was

45 longer for the first years of life. The mean costal index decreased by $21 \%$ for subjects over three

46 years old compared to those under three $\left(p<10^{-4}\right)$. The volume of the sternebrae was found to be

47 highly age dependent. Such data could be useful to define the standard geometry of the paediatric

48 thorax and help to detect clinical abnormalities.

49 Keywords: child; rib; cartilage; thorax; sternum 


\section{1. Introduction}

53 The thoracic anatomy of children is clinically important in spinal deformities such

54 as scoliosis, and anatomical measurements can be used to identify normal

55 geometry, quantify the severity of deformity, evaluate pulmonary capacity or

56 build models for orthopedic or surgical treatment. Moreover, the thorax contains

57 and protects vital organs and can be injured when subjected to impact, as in motor

58 vehicle accidents. For children, the thorax is the second most often injured

59 segment in crash events [5].

60 Child external morphology is well known, and some specific databases

61 have been created to design child dummies [9, 26, 29]. However costal cartilage

62 and sternal anatomy are generally not assessed, even though they can be of

63 primary importance. The rib ossification process progressively increases the

64 stiffness of the thorax and sets final thoracic geometry. During ribcage

65 ossification, the large difference in material properties between cartilage and bone

66 affects the stiffness of the rib cage, which is important when considering the

67 orthotic brace effect or response to an impact in children.

68 Child thorax geometry is often described to highlight specific

69 abnormalities (scoliosis, pectus carinatum and pectus excavatum), but quantitative

70 descriptions of child ribcages are rare, while they are essential to build numerical

71 models or to identify normal patterns for different age groups. Only a few existing

72 studies provide descriptive parameters of the child rib cage. Derveaux et al. used

73 2D measurements on lateral X-rays to evaluate the anteroposterior width of the

74 thorax [11]. On CT-Scan slices, Haller et al. defined an index to describe the ratio

75 between the transversal and anteroposterior diameters [14], but did not find any 
76 correlation with age in a group of 19 patients. Using the same method on 574

77 child CT-scans, Daunt et al. found a smaller Haller index for children under two,

78 but a higher index for girls of 0-6 and 12-18 years compared to boys of the same

79 ages [8]. In 1989, Stokes et al. studied the 3D geometry of 71 scoliotic rib cages,

80 compared to 10 controls composed of six cadavers and four volunteers (aged 26 to

$8154)$, using stereoradiography reconstruction modeling with $0-20^{\circ}$ incidences [28].

82 Costal cartilage dimensions were estimated from direct measurements on four 83 adult cadavers. Using a similar technique, Delorme et al. studied the effect of

84 surgical correction on the shape of the ribcages of 29 adolescents (mean age $15 \pm$

851.5 years) by calculating the 3D rotations of the ribs [10]. Costal cartilages were

86 not included in the reconstructions. Bertrand et al. performed more precise 3D rib

87 cage reconstructions on 15 asymptomatic adults (mean age $27 \pm 8$ years), using

88 two simultaneous perpendicular planar X-rays from the EOS system (Biospace

89 Instruments, Paris, France) [3]. While various geometric parameters described the

90 ribs, the costal cartilage and sternum were not investigated, due to the lack of

91 visibility. Due to the superimposition of bone structures and the high quantity of

92 radiotransparent cartilage, it is difficult to have a precise quantitative description

93 of child cartilage using standard X-rays.

94 Another anatomic part of the thorax is the sternum, which influences the

95 global stiffness of the rib cage, and can be used as an osseous age estimator. In

96 1967, Riach found a high age correlation with the surface of the sternebrae in 23

97 specimens aged between 26 weeks of pregnancy and six-years-old [23].

98 Nevertheless, the number and time of appearance of the sternebrae show high

99 variations from one child to another; so it seemed not to be a relevant bone-age

100 indicator [1, 21-24].

101 To take into account growth of cartilage and bone, it is essential to have a 
102 better geometrical description of the child ribcage. Thus, the aim of this study is to

103 quantify the 3D geometry and to study the age effect of the child rib cage:

104 including sternum, ribs and costal cartilage, using reconstructions from CT-Scan 105 data.

107 2. Methods

108 2.1. Population

109 Forty-eight thoracic CT-scans of children aged from four months to 15 years (22

110 girls, 26 boys) were collected and anonymized in the Necker Hospital (Paris,

111 France). The CT-scans had previously been performed on medical prescriptions

112 with consecutive slices of 4 or $5 \mathrm{~mm}$ thickness. The clinical prescriptions for CT-

113 scans of the thorax were: severe asthma, acute respiratory distress syndrome,

114 investigation of intrathoracic lymph nodes, inhaled foreign body, trauma with no

115 bone lesion, staging of primary extrathoracic malignancies. CT-scans in children

116 with syndromes or heart congenital lesions were excluded. CT-scans showing

117 thorax abnormalities or recent surgery were not included. Four groups of 12

118 children were defined according to age: four months to three years (A group), four

119 to seven years (B group), eight to 11 years (C group) and then 12 to 15 years old 120 (D group).

\section{$121 \quad$ 2.2. 3D reconstruction method}

122 An automatic segmentation and reconstruction of the ribs and ossified sternebrae 123 was performed on each transversal plane using Avizo software (V5, VSG, USA), 124 with further manual corrections at the boundaries of the sternebrae. A manual 125 segmentation of the costal cartilages was accomplished to assess both their shape 
126 and the junction to the sternum. This thorough segmentation was performed by a

127 pediatric orthopedic surgeon previously trained in radiological identifications and

128 supervised by a pediatric radiologist. A total of 113 sternal sternebrae, 960 ribs

129 and 518 costal cartilages were reconstructed. The sternal cartilage and some costal

130 cartilage were not considered because incomplete or too difficult to discern on the

131 CT-scan images (Table 1). In order to assess the reliability of the resulting

132 sternebrae volume, 102 sternebrae were reconstructed twice, four weeks apart.

\section{2.3. Data processing and calculated parameters}

135 From the 3D reconstructions, each rib was modeled by its mid-line, according to

136 the following steps (Figure 1):

137 1. The least square circle of the rib was calculated, defining center $\mathrm{O}$ and plane $138 \quad$ A

1392 . From the anterior to the posterior extremities, fifty equidistant-angle planes $P_{i}$ 140 rotating through $\mathrm{O}$, orthogonal to plane $\mathrm{A}$, were created.

1413 . Fifty corresponding cross sections $S_{i}$ were calculated as the intersection of 142 planes $P_{i}$ and the external 3D surface of the rib.

143 4. The rib mid-line was constructed as the geometric centroid of all $\mathrm{S}_{\mathrm{i}}$ sections.

144 Applied to all left and right ribs, a wireframe of the thorax was then 145 constructed (Figure 2). A similar method was applied to calculate the costal 146 cartilage mid-line. Unlike ribs, costal cartilages are not curved in the transversal 147 plane, so the intersection planes were then defined as parallel to the sagittal plane.

148 Rib cage morphometry was described by three parameters: maximum

149 anteroposterior width, maximum lateral width, and thoracic index, their ratio. The 150 local quantitative description of the ribs and the costal cartilage was calculated 
151 using rib mid-line length, chord length, enclosed area, maximum width, frontal

152 and lateral orientations of the rib $[3,7,16,18]$. In order to estimate the relative

153 length of the cartilage, the costal index was defined: for each rib, it describes the

154 ratio between the cartilage mid-line length and the whole costal segment, i.e. rib

155 and cartilage mid-line lengths.

\section{$156 \quad$ 2.4. Statistical analysis}

157 Because no assumption was made regarding the distribution of the data, the

158 Kruskal-Wallis test was used to assess the statistical significance of differences in

159 terms of gender, laterality, age group and rib level; with a threshold $p$-value below

$160 \quad 0.05$ being used to denote significance.

\section{3. Results}

\section{$162 \quad 3.1$. Reconstruction assessment}

163 The reproducibility study performed on 102 sternal elements showed a mean

164 volume difference of $2.7 \%(\max 9.9 \%$, Standard Deviation $2.3 \%)$, i.e. $0.2 \mathrm{~cm}^{3}$ $165\left(\max 2.0 \mathrm{~cm}^{3}, \mathrm{SD} 0.4 \mathrm{~cm}^{3}\right)$.

\section{3.2. Sternebrae distribution}

167 Most of the sternums presented a manubrium composed of one sternebra and a

168 mesosternum composed of three sternebrae. A high variability of anatomical

169 configurations was found. For example, Figure 3 shows one immature sternum (a.

170 subject 10; 3-years-old), two sternums with merged sternebrae (b. subjects 33 and

$17118 ; 10$ and 5-years-old respectively), and two early-adult sternums (c. subjects 26

172 and 28; 8 and 9-years-old respectively). In three cases, the manubrium had two

173 ossification centers in a vertical disposition. The uppermost part of the

174 mesosternum was always composed of a single ossification center. The lowest 
175 part of the mesosternum often exhibited lateral or/and longitudinal bifid

176 ossification centers. The xiphoid process was already ossified in seven cases

177 before six years old (out of 18 cases).

178 While the distribution of the sternebrae was found to be highly variable, Figure 4

179 shows the evolution of the sternebrae volumes of each sternum during growth. A

180 global increase was observed and an exponential equation was fitted to describe

181 sternum volume versus age relation of the studied population. The volumes were

182 significantly different between all age groups $\left(p<10^{-4}\right)$ and the volume of the 15 -

183 year-old sternum is about 10 times the volume at birth. Furthermore, dispersion is

184 higher for the oldest patients. No significant difference was found between girls

185 and boys with regard to the sternal volume distribution $(\mathrm{p}>0.8)$.

\section{$186 \quad 3.2$. Ribs and rib cage geometry}

187 Statistical tests did not show significant differences for any parameter, either for 188 gender $(p>0.15)$ or laterality $(p>0.95)$. Consequently, in the first approach, no 189 distinction is made between girls and boys, left and right ribs or costal cartilages.

190 The global parameters of the rib cages are summed up in Table 1. The 191 lateral (LAT) and anteroposterior (AP) widths increase with age, but the thoracic 192 index shows a very small increase during growth.

193 In Figure 5, the mean and SD costal index is plotted for each rib level by 194 age group. For all groups, the costal index decreases from rib level 1 to 3 and 195 increases from level 3 to 7 . Furthermore, the costal index is higher for the first 196 years of life, with an almost equal length of cartilage and bone for levels 1 and 6 197 (ratio of $47 \%$ and $45 \%$ respectively) for group A. Level 7 has the longest 198 cartilage region in the youngest group with a ratio of $60 \%$. For all levels, the 199 mean costal index decreases significantly by $21 \%$ between groups A ( 0 to 3 years 
old) and B (4 to 7 years old) $\left(p<10^{-4}\right)$.

In Figure 6, the progression of ribcage parameters is plotted by age group

202 and rib level. Rib area, rib mid-length, maximum width and chord length increase

203 with age. Rib angles show a small variation in the present population. All the

204 parameters have a similar pattern of evolution regarding rib level. The statistical

205 significance of differences between adjacent groups (A-B, B-C and C-D) have

206 been calculated (Table 2): the geometric rib parameters are significantly different

$207\left(\mathrm{p}<10^{-4}\right)$ between two adjacent groups, except for the frontal and lateral angles.

208 With respect to costal and cartilage parameters, Table 3 (supplementary 209 material) sums up the mean values and standard deviations of all calculated

210 parameters. Except for the frontal and lateral orientations of the rib, the mean

211 values of all costal parameters increase from level 1 to level 6, and then decrease 212 from level 7 to level 10. Cartilage length increases with the rib level, from level 1 213 to 7.

\section{4. Discussion}

216 This study characterizes the bony and cartilaginous structures of the child thorax

217 during its growth, from CT-scan data. Even if the subjects in this cohort were not

218 fully healthy, the CT-scans were prescribed for a list of indications that do not

219 affect the ribcage geometry. Performing CT-scans in healthy children without

220 clinical indication is not possible due to ethical considerations. In this study, only

221 CT-scans performed for limited pathologies were collected, while patients with

222 chest malformations or chronic diseases with potential consequences for the

223 child's growth were excluded. The dataset is therefore believed to be pertinent to

224 represent non-pathological geometries of the child ribcage. The number of 
225 subjects is large (48) and covers a wide range of ages, from four months to 15

226 years, with three subjects per year. The gender distribution of the study population

227 is well balanced. The reconstructions made using the Avizo software have been

228 validated by an intra-observer reproducibility study on 102 sternebrae. Although

229 the detection of bone pixels was automatic, an operator correction was required

230 when two different bone structures were in contact. It was then necessary to

231 distinguish boundaries manually.

232 As expected, the results show an increase of all parameters with growth.

233 The originality of this study lies in its quantitative approach. The thoracic index of

234 the present study shows a slight evolution during growth, up to 11 years; it then

235 stabilizes (Table 1). Furthermore, the thoracic index shows no significant

236 evolution between children and adults: Bertrand et al. (2008) evaluated this

237 parameter at a mean value of 0.63 (SD 0.07) on 15 adults (mean age: 27 years, SD

2388 years), whereas the present child population shows a mean thoracic index of

2390.65 (SD 0.05). The thicknesses of the ribs were not taken into account in the

240 present study; therefore the maximum anteroposterior and lateral widths of the

241 thorax morphometric parameters have been slightly underestimated.

242 The evolution of all the costal parameters for each rib level are compared

243 to a young asymptomatic adult population [3] (Figure 6). The mean growth speed,

244 observed as the distance between the different curves of the same parameter, is

245 not the same between groups, depending on the parameter considered. The

246 differences between 2 adjacent age groups are significant except for frontal and

247 lateral angles (Table 2). Because various body parts are known to have different

248 growth timing $[4,6]$, no assumptions were made with respect to the growth shape

249 or the variations between the various parameters, even if global growth was

250 expected. Therefore due to the similar proportions in the ribcage dimensions 
251 between children and adults, child geometric data can be built from that of adults 252 using an appropriate scaling factor. Comparison of frontal and lateral angles with adults is difficult due to

254 differences in methodology: while Bertrand et al. studied biplanar X-rays in 255 standing position, the present study is based on CT-scan data, performed on 256 children in a lying position [3]. This is the main limitation of this study: CT-scans 257 were performed in a lying position, together with the unknown respiratory phase 258 during acquisition. These conditions require a careful interpretation of the angular 259 parameters of ribs in frontal and sagittal planes, as the effect of the posture on the 260 thoracic structures (supine versus upright versus seated) has already been 261 underlined $[2,17]$. Similarly, for the youngest children, the presence of clothing 262 or diaper can change the natural angle of the ribs, as well as the anteroposterior 263 diameter of the rib cage, as calculated. However, the other parameters are not 264 affected by the lying position as they are calculated using the rib and cartilage 265 mid-lines. The costal index presented in this study gives the cartilage length for 266 the corresponding rib length, for a specific age and rib level. This result - rarely 267 reported in the literature - is essential in a model design because cartilage is a 268 chest component with different mechanical properties and behavior from ribs that 269 are ossified [13]. The current results allow estimates based on in vivo 270 measurements.

271 The sternum is a structure that gradually ossifies. According to the 272 literature, the number and distribution of sternebrae vary with growth. In 1967, by 273 taking anteroposterior radiographs of specimens excised at necropsy, Riach found 274 a correlation between the sum of the sternebrae surfaces and age, especially for 275 the youngest children, less than six years old [23]. Considering the total volume of 276 the sternebrae (Figure 4), the present study completes this trend for older children, 
277 up to age 15 . Contrary to the number of sternebrae, the volume of the bony parts

278 of the sternum is found to be a good age-predictive parameter, especially for the

279 youngest. An exponential trend fits with age for the population studied. The

280 consequences of growth will probably decline after puberty. Due to the high

281 sensitivity of the results to the age, any conclusion on a gender effect would be

282 uncertain: the age effect will overwhelm the gender effect.

283 Results from the present study could help to complete missing data or to

284 validate numerical child models. Indeed, various models from the literature used

285 X-rays to reconstruct the 3D geometry of the bony structures of the child rib cage

$286[12,16]$. The costal cartilage, not visible on standard X-rays, is then often

287 approximated. When geometry is unknown in a child model, it is often scaled 288 from the adult ones $[15,27,30]$. Besides the known ratio variation of the 289 geometry and mass of the body segments with growth [6, 25], children's ribcages

290 contain a substantial quantity of growth cartilage, which has different material 291 properties. The present results provide new quantitative data on child ribcage 292 geometry which will assist in building more relevant child numerical models.

293 To refine the interpretation of the results, it would have been interesting to 294 distinguish between girls and boys according to their respective puberty growth.

295 However, it then would have been necessary to obtain data on a higher number of 296 patients that had passed the peak of puberty, until 17 or 18 years old. The same 297 protocol could be used in further studies for such assessment.

298 Finally, the present study highlighted the cartilaginous preponderance and 299 the evolution of the young thorax geometry compared to that of adults. Thus such 300 data could help to improve the biofidelity of child models for the thoracic 301 segment. Future applications could be considered, like the improvement of Finite 302 Element Models [19], physical dummies for CPR training [20], forensic analysis, 
303 or to define the standard geometry of the paediatric thorax and help to detect 304 clinical abnormalities.

305

\section{Acknowledgements}

307 The authors gratefully acknowledge the kind review of C. Adam. This research was partly funded 308 by a grant from the ANR (SECUR_ENFANT 06_0385) and supported by the GDR 2610 309 "Biomécanique des chocs" (CNRS/INRETS/GIE PSA Renault).

310 


\section{References}

312

313

314 1. Ashley G. T. (1956) The relationship between the pattern of ossification

315

316

317

318

319

320

321

322

323

324

325

326

327

328

329

330

331

332

333

334

335

336

337

338

339

340

341

342

343

344

345

346

347

348

349

350

351

352

353

354

355

356 and the definitive shape of the mesosternum in man. J Anat 90:87.

2. Beillas P., Lafon Y., Smith F. W. (2009) The effects of posture and subject-to-subject variations on the position, shape and volume of abdominal and thoracic organs. Stapp Car Crash J 53:127-54.

3. Bertrand S., Laporte S., Parent S. et al (2008) Three-dimensional reconstruction of the rib cage from biplanar radiography. IRBM 29(4):278.

4. Beusenberg M. C., Happee R., Twisk D. et al. Status of injury biomechanics for the development of child dummies. in Child Occupant Protection Symposium. 1993. San Antonio, Texas, USA.

5. Brown J. K., Jing Y., Wang S. et al (2006) Patterns of severe injury in pediatric car crash victims: Crash Injury Research Engineering Network database. J Pediatr Surg 41(2):362-7.

6. Burdi A. R., Huelke D. F., Snyder R. G. et al (1969) Infants and children in the adult world of automobile safety design: pediatric and anatomical considerations for design of child restraints. J Biomech 2(3):267-80.

7. Dansereau Jean, Stokes Ian A. F. (1988) Measurements of the threedimensional shape of the rib cage. Journal of Biomechanics 21(11):893.

8. Daunt S. W., Cohen J. H., Miller S. F. (2004) Age-related normal ranges for the Haller index in children. Pediatric Radiology 34(4):326.

9. de Jager Kate, van Ratingen Michiel, Lesire Philippe et al. Assessing new child dummies and criteria for child occupant protection in frontal impact. in 19th ESV Conference. 2005. TNO - LAB - BASt - IDIADA - UTAC.

10. Delorme S., Violas P., Dansereau J. et al (2001) Preoperative and early postoperative three-dimensional changes of the rib cage after posterior instrumentation in adolescent idiopathic scoliosis. European spine journal : official publication of the European Spine Society, the European Spinal Deformity Society, and the European Section of the Cervical Spine Research Society 10(2):101-7.

11. Derveaux L., Clarysse I., Ivanoff I. et al (1989) Preoperative and postoperative abnormalities in chest $\mathrm{x}$-ray indices and in lung function in pectus deformities. Chest 95(4):850.

12. Dworzak J., Lamecker H., von Berg J. et al (2010) 3D reconstruction of the human rib cage from $2 \mathrm{D}$ projection images using a statistical shape model. International journal of computer assisted radiology and surgery 5(2):111-24.

13. Forman J. L., Kent R. W. (2011) Modeling costal cartilage using local material properties with consideration for gross heterogeneities. J Biomech 44(5):910-6.

14. Haller J. A., S. Kramer S., A. Lietman S. (1987) Use of CT scans in selection of patients for pectus excavatum surgery: a preliminary report. J Pediatr Surg 22(0022-3468). 
15. Irwin Annette L., Mertz Harold J. Biomechanical bases for the CRABI and Hybrid III child dummies. in 41st Stapp Car Crash Conference. 1997. Lake Buena Vista, Florida, USA.

360 16. Jolivet E., Sandoz B., Laporte S. et al (2010) Fast 3D reconstruction of the rib cage from biplanar radiographs. Med Biol Eng Comput 48(8):821-8.

17. Lafon Y., Smith F. W., Beillas P. (2010) Combination of a modeldeformation method and a positional MRI to quantify the effects of posture on the anatomical structures of the trunk. J Biomech 43(7):126978.

18. Mitton D., Zhao K., Bertrand S. et al (2008) 3D reconstruction of the ribs from lateral and frontal X-rays in comparison to 3D CT-scan reconstruction. J Biomech 41(3):706-10.

19. Mizuno K., Iwata K., Deguchi T. et al (2005) Development of a threeyear-old child FE model. Traffic Inj Prev 6(4):361-71.

20. Nishisaki Akira, Nysaether Jon, Sutton Robert et al (2009) Effect of mattress deflection on CPR quality assessment for older children and adolescents. Resuscitation 80(5):540.

21. O'Neal M. L., Dwornik J. J., Ganey T. M. et al (1998) Postnatal development of the human sternum. Journal of Pediatric Orthopaedics 18(3):398.

22. Ogden J. A., Conlogue G. J., Bronson M. L. et al (1979) Radiology of postnatal skeletal development - II. The manubrium and sternum. Skeletal Radiology 4(4):189.

23. Riach I. C. (1967) Ossification in the sternum as a means of assessing skeletal age. Journal of Clinical Pathology 20(4):589.

24. Rush W. J., Donnelly L. F., Brody A. S. et al (2002) "Missing" sternal ossification center: Potential mimicker of disease in young children. Radiology 224(1):120.

25. Sandoz B., Laporte S., Skalli W. et al (2010) Subject-specific body segment parameters' estimation using biplanar X-rays: a feasibility study. Comput Methods Biomech Biomed Engin 13(6):649-54.

26. Saul Roger A., Pritz Howard B., McFadden Joeseph et al. Description and performance of the Hybrid III three-year-old, six-year-old and small female test dummies in restraint system and out-of-position air bag environments. in 16th International Technical Conference on the Enhanced Safety of Vehicles. 1998. NHTSA (National Highway Traffic Safety Administration).

27. Schneider K., Zernicke R. F. (1992) Mass, center of mass, and moment of inertia estimates for infant limb segments. J Biomech 25(2):145-8.

28. Stokes I. A., Dansereau J., Moreland M. S. (1989) Rib cage asymmetry in idiopathic scoliosis. Journal of orthopaedic research : official publication of the Orthopaedic Research Society 7(4):599-606.

29. van Ratingen Michiel R., Twisk Dirk, Schrooten Mark et al. Biomechanically based design and performance targets for a 3-year-oldchild crash dummy for front and side impact. in Second Child Occupant Protection Symposium. 1997. Lake Buena Vista, Florida, USA.

30. Wang Y., Rangarajan N., Shams T. et al (2005) Design of a biofidelic instrumented $3.4 \mathrm{~kg}$ infant dummy, NHTSA (National Highway Traffic Safety Administration). 


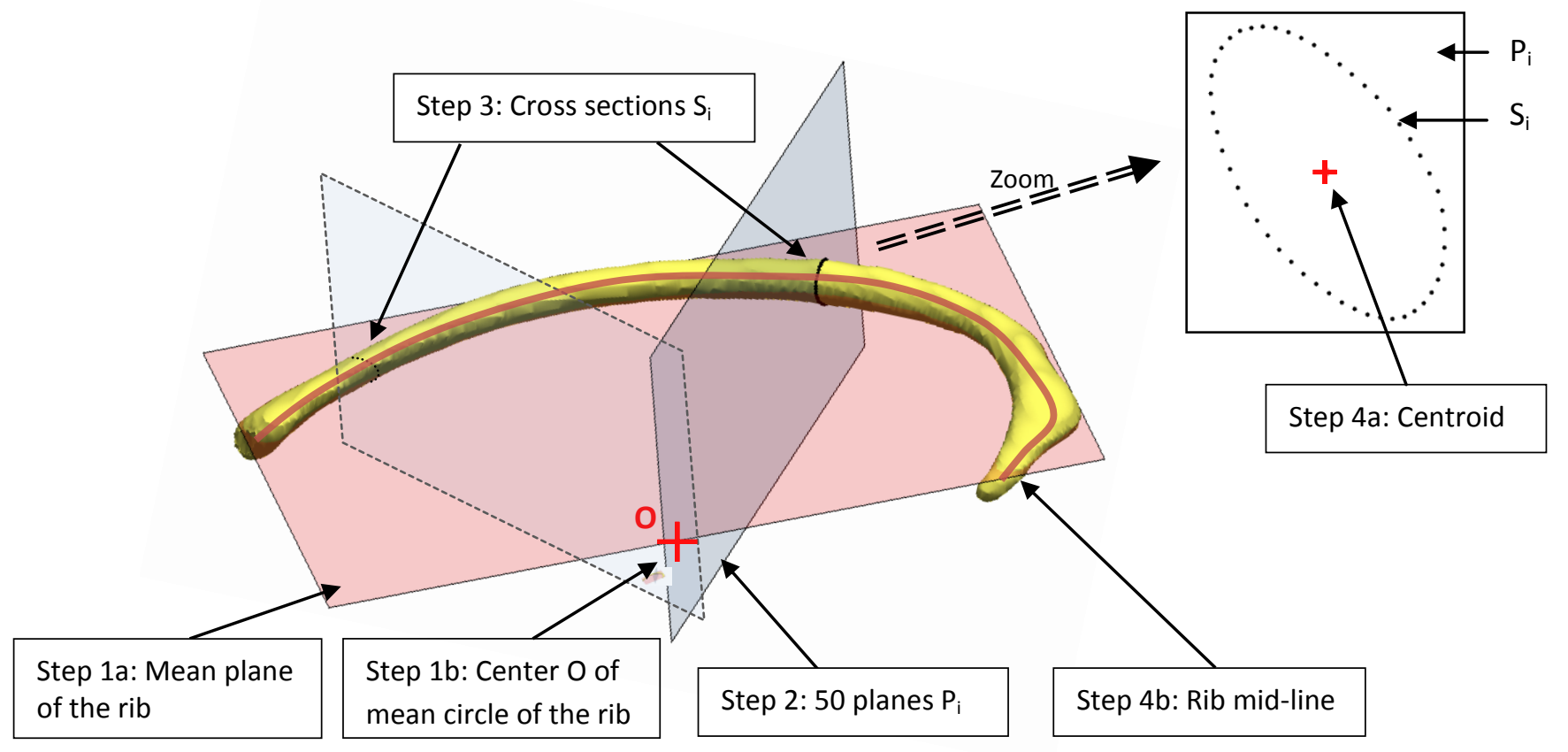

Figure 1: Rib mid-line calculation steps. 

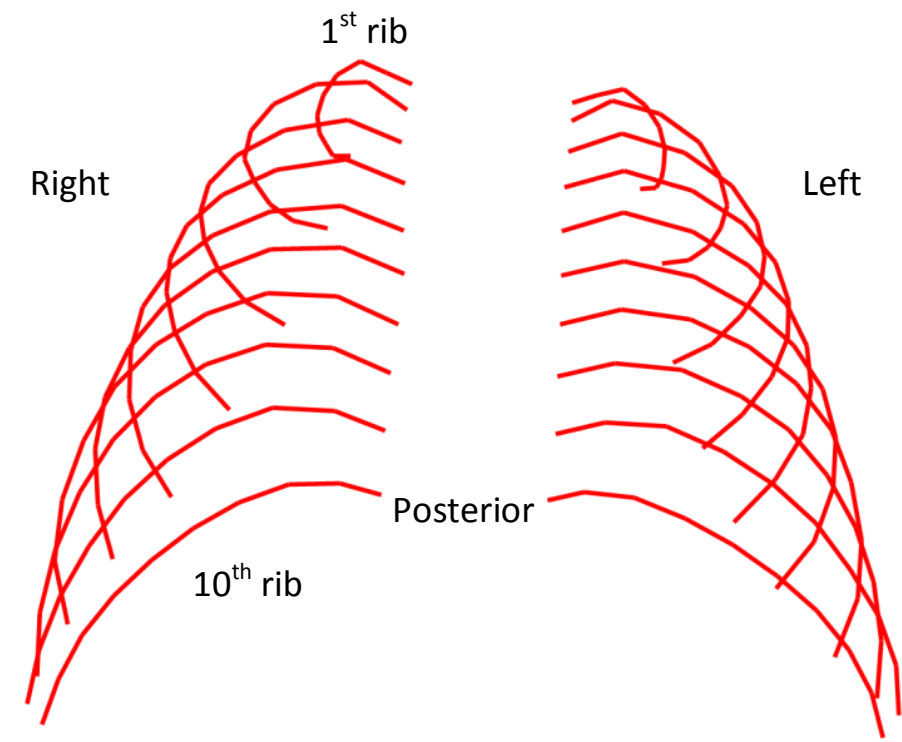

Anterior

Figure 2: Calculated mid-lines rib cage (patient 10). 


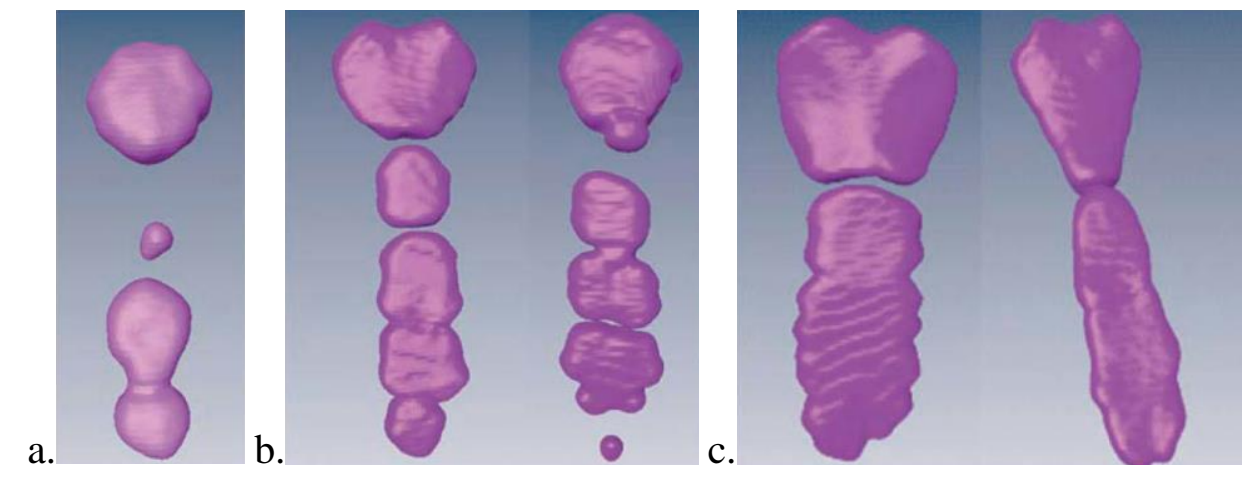

Figure 3: Various sternum configurations, high variability not correlated to age.

a. immature sternum ( 3 years old); b. merged sternebrae (10 and 5 yo); c. early-adult sternums (8 and 9 yo). 


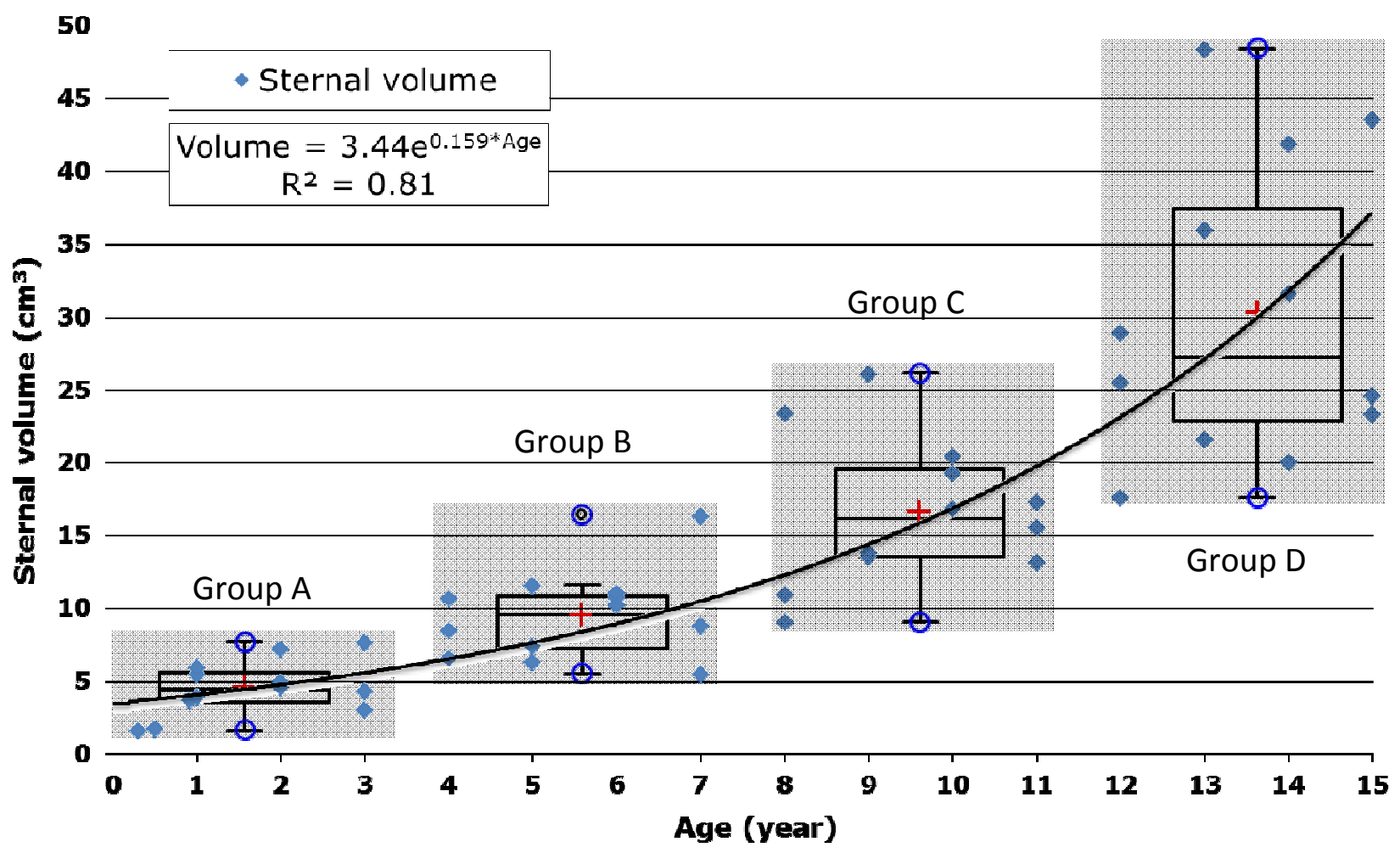

Figure 4: Measured sternebrae volume evolution with age, and boxplots by age groups. Group A: 0.3 to 3 years old; Group B: 4-7 yo; Group C: 8-11 yo; Group D: $12-15$ yo. The volumes are significantly different between all age groups $\left(p<10^{-4}\right)$. 


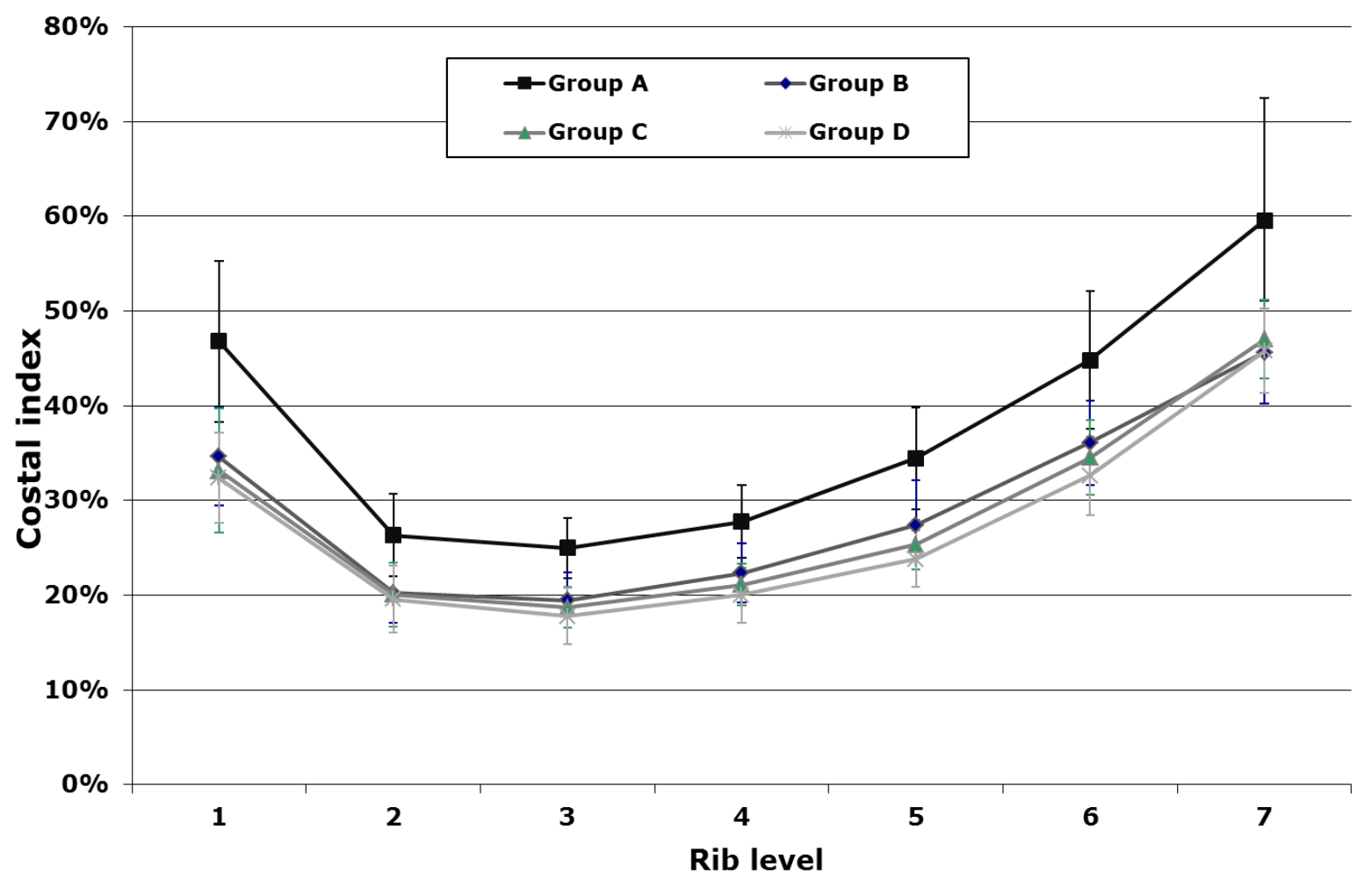

Figure 5: Costal index (mean and standard deviation) function of rib level and age group. Group A: 0.3 to 3 years old; Group B: 4-7 yo; Group C: 8-11 yo; Group D: 12-15 yo. 

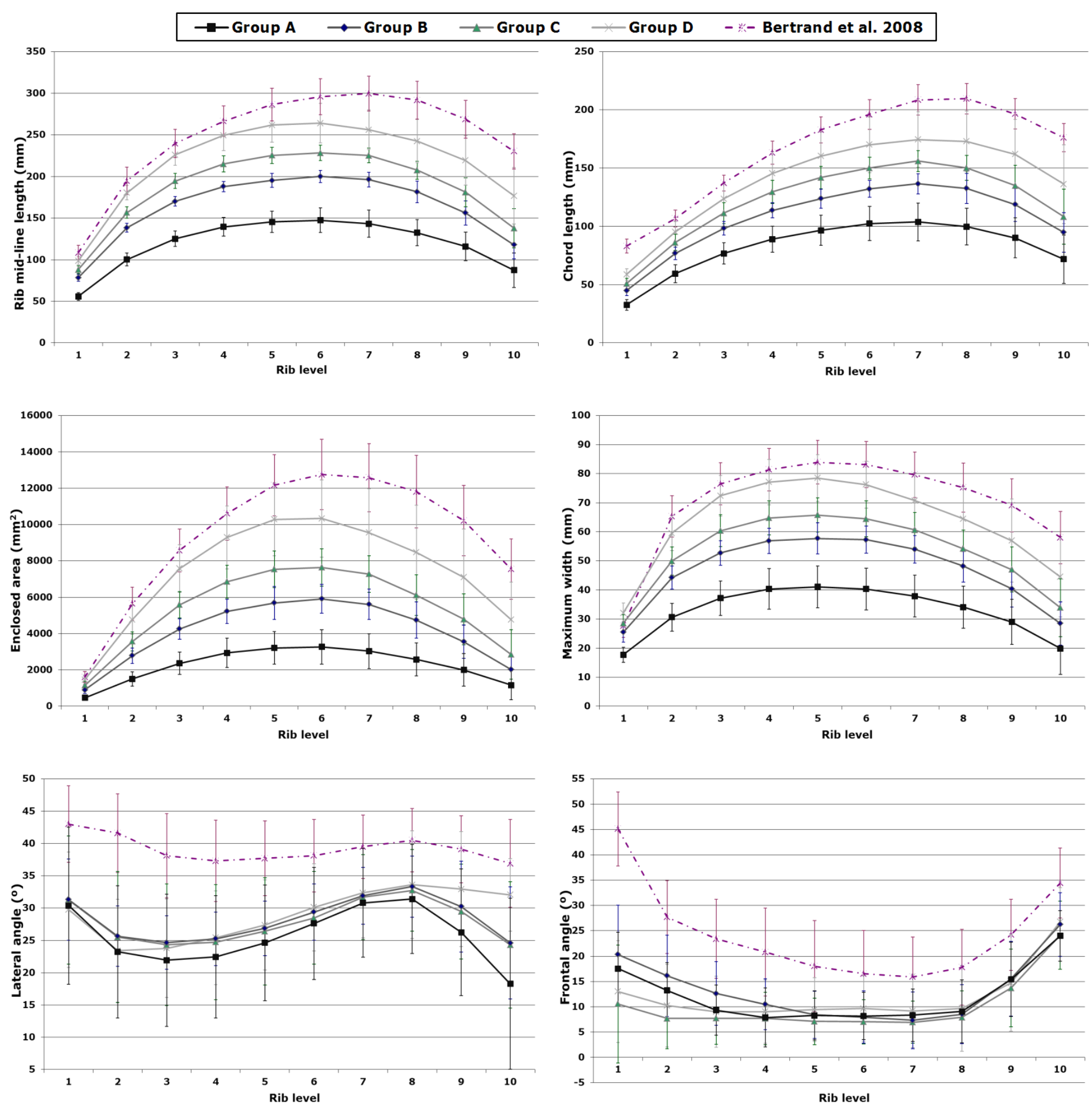

Figure 6: Evolution of parameters and comparison with the literature, function of rib level and age group (mean and standard deviation). Group A: 0.3 to 3 years old; Group B: 4-7 yo; Group C: 8-11 yo; Group D: 12-15 yo; Bertrand et al. (2008): 27 yo (SD 8 yo). 
Supplementary material - Table 3: Mean (SD) rib and cartilage calculated parameters, 3 children per age group.

\begin{tabular}{|c|c|c|c|c|c|c|c|c|c|c|c|c|c|c|c|c|c|}
\hline \multicolumn{2}{|c|}{ Data Rib level } & $<1$ & 1 & 2 & 3 & 4 & 5 & 6 & 7 & $\frac{\text { ear) }}{8}$ & 9 & 10 & 11 & 12 & 13 & 14 & 15 \\
\hline \multirow{10}{*}{ 产 } & 1 & $45.0(5.6)$ & $57.5(2.9)$ & $58.1(3.1)$ & $62.9(1.6)$ & $79.4(14.1)$ & $76.1(5.9)$ & $76.1(3.6)$ & $81.7(8.5)$ & $86.3(8.9)$ & $85.5(7.4)$ & $85.6(8.8)$ & $94.9(3.5)$ & $89.6(9.1)$ & $103.0(4.7)$ & $100.8(7.4)$ & $100.8(7.5)$ \\
\hline & 2 & $80.7(9.4)$ & $100.3(9.7)$ & $107.3(5.4)$ & 112.5 (5.3) & 131.8 & $140.4(8.9)$ & $134.1(5.1)$ & $146.7(11.6)$ & $151.4(12.2)$ & $146.1(8.9)$ & $159.0(6.1)$ & $170.1(3.7)$ & $166.1(15.0)$ & $189.4(10.4)$ & $183.9(9.0)$ & $182.3(21.1)$ \\
\hline & 3 & $99.9(10.4)$ & $124.9(10.3)$ & $135.4(4.7)$ & $140.4(5.7)$ & $161.6(13.1)$ & $170.8(9.6)$ & $166.4(4.3)$ & $181.6(10.2)$ & $186.8(13.9)$ & $184.0(9.8)$ & $200.2(3.9)$ & $207.1(2.1)$ & 206.8 (13.7) & $234.2(18.0)$ & $234.4(10.7)$ & $228.5(26.9)$ \\
\hline & 4 & 109.1 (11.5) & $138.3(10.9)$ & $152.5(4.8)$ & $157.3(6.9)$ & $178.6(13.2)$ & $188.0(10.2)$ & $183.4(4.0)$ & $201.2(8.7)$ & $205.6(15.6)$ & 204.1 (11.9) & $224.3(4.5)$ & $225.9(2.8)$ & $226.5(16.8)$ & $258.2(24.1)$ & 262.6 & 250.5 \\
\hline & 5 & $113.0(12.1)$ & $144.3(8.8)$ & $161.4(4.6)$ & $162.7(9.0)$ & $186.0(12.9)$ & $196.6(10.9)$ & $186.3(17.4)$ & 212.1 (9.2) & $215.3(17.9)$ & $217.4(15.4)$ & $235.1(5.4)$ & $233.5(4.7)$ & $236.7(16.4)$ & $275.4(25.6)$ & $273.8(10.8)$ & $261.4(31.2)$ \\
\hline & 6 & $112.7(12.3)$ & $146.2(6.8)$ & $163.5(6.0)$ & $166.9(8.3)$ & $189.2(13.5)$ & $201.4(10.5)$ & $195.7(3.8)$ & $213.9(10.9)$ & $219.4(18.3)$ & $220.5(15.0)$ & $238.5(3.0)$ & $234.9(7.5)$ & $239.2(15.1)$ & $277.4(31.3)$ & 275.9 (9.5) & 263.4 (34.7) \\
\hline & 7 & $110.2(12.7)$ & $135.4(9.4)$ & $160.5(6.4)$ & $166.7(7.7)$ & 185.6 & $194.9(16.1)$ & $193.1(3.7)$ & 211.1 (11.2) & $215.3(18.0)$ & $217.9(15.2)$ & 234.5 (1.8) & 233.0 & 234.1 (13.8) & $257.2(49.5)$ & $270.5(9.4)$ & $262.3(35.9)$ \\
\hline & 8 & $104.4(12.4)$ & $122.3(16.0)$ & $146.9(10.8)$ & $155.9(12.3)$ & $177.1(13.2)$ & $178.2(25.8)$ & $176.9(12.9)$ & $193.4(23.2)$ & $188.2(12.1)$ & $203.8(16.1)$ & $225.8(1.1)$ & $211.9(16.1)$ & $223.0(12.0)$ & $233.7(68.1)$ & $259.0(9.4)$ & 253.4 (34.5) \\
\hline & 9 & $95.1(11.3)$ & $100.9(20.3)$ & $128.4(22.3)$ & $139.0(18.8)$ & $157.6(7.3)$ & $154.1(31.8)$ & 155.5 (19.5) & $156.9(25.7)$ & $152.4(8.4)$ & $180.9(20.4)$ & $207.6(5.6)$ & $183.0(32.6)$ & $202.7(10.7)$ & $203.7(85.8)$ & $237.5(8.2)$ & $233.1(27.9)$ \\
\hline & 10 & $80.9(8.4)$ & $60.7(16.9)$ & $97.4(34.4)$ & $110.6(25.9)$ & $124.4(8.8)$ & $115.2(32.2)$ & $122.8(20.5)$ & $109.0(30.8)$ & $103.3(7.4)$ & $139.0(20.7)$ & $174.3(6.7)$ & $140.2(41.5)$ & $162.6(9.6)$ & $148.9(85.8)$ & $199.5(7.6)$ & 195.6 (19.7) \\
\hline \multirow{6}{*}{ 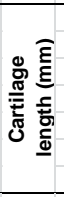 } & 1 & $22.8(2.9)$ & $27.2(0.1)$ & $25.6(3.6)$ & $27.3(2.8)$ & $27.0(0.8)$ & $29.5(3.0)$ & $24.0(3.4)$ & $26.6(1.3)$ & $32.8(4.2)$ & $29.8(6.3)$ & $27.2(5.2)$ & $22.4(4.1)$ & $28.9(4.0)$ & $32.7(3.4)$ & $33.0(5.5)$ & $32.6(4.9)$ \\
\hline & 2 & $23.7(3.8)$ & $28.1(1.0)$ & $27.1(2.9)$ & $26.8(2.9)$ & $28.6(2.5)$ & $26.9(3.5)$ & $25.9(5.5)$ & $29.6(3.6)$ & $32.7(1.1)$ & $30.8(6.2)$ & $30.4(4.1)$ & $28.5(0.6)$ & $30.9(4.1)$ & $34.2(5.0)$ & $37.8(6.0)$ & $37.4(5.0)$ \\
\hline & 3 & $28.1(3.6)$ & $34.3(1.3)$ & $32.1(2.0)$ & 30.9 (3.2) & $35.3(1.9)$ & $32.2(5.4)$ & $32.0(7.2)$ & $33.6(1.5)$ & $37.6(2.2)$ & $35.5(6.2)$ & $35.4(2.9)$ & $34.4(1.0)$ & $35.3(2.6)$ & $39.0(5.8)$ & $42.4(6.8)$ & $42.8(5.9)$ \\
\hline & 5 & $42.5(4.0)$ & $56.4(4.4)$ & $48.9(2.9)$ & $53.7(10.3)$ & $56.0(1.9)$ & $52.4(8.0)$ & $53.9(8.7)$ & $52.1(5.0)$ & $59.5(4.6)$ & $55.4(4.3)$ & $54.1(4.6)$ & $57.7(3.4)$ & $55.6(2.8)$ & $61.2(8.3)$ & $65.7(8.4)$ & $66.0(9.0)$ \\
\hline & 6 & $60.2(5.5)$ & $73.9(6.9)$ & $65.6(2.6)$ & $63.7(0.7)$ & $76.2(1.8)$ & 71.5 (11.8) & $64.2(2.1)$ & $74.9(5.9)$ & $83.2(3.2)$ & $74.2(5.5)$ & $75.6(7.9)$ & $82.7(4.2)$ & $80.0(4.4)$ & $78.2(6.6)$ & $90.7(9.5)$ & $94.0(11.0)$ \\
\hline & 7 & $70.7(1.2)$ & & $87.1(2.4)$ & 79.4 & & $98.3(24.0)$ & $83.6(4.4)$ & $100.7(9.3)$ & & $105.2(9.0)$ & $105.7(10.3)$ & & $114.0(9.0)$ & $110.6(9.2)$ & $128.7(7.2)$ & $125.1(11.1)$ \\
\hline \multirow{10}{*}{ 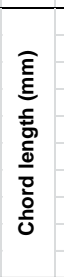 } & 1 & $26.0(3.1)$ & $34.3(1.0)$ & $33.8(2.2)$ & $36.5(2.2)$ & $44.3(6.8)$ & $43.9(2.2)$ & $45.6(4.7)$ & $45.9(2.3)$ & $49.8(5.0)$ & $49.8(5.0)$ & $48.9(3.8)$ & $55.1(1.4)$ & $55.4(4.4)$ & $62.3(4.1)$ & $59.9(4.6)$ & $57.3(3.9)$ \\
\hline & 2 & $47.8(4.6)$ & $61.3(2.7)$ & $63.7(4.8)$ & $64.5(2.4)$ & $73.1(5.7)$ & $77.3(5.1)$ & $77.7(5.0)$ & $79.1(4.2)$ & $83.0(5.0)$ & $82.9(7.7)$ & $84.5(3.0)$ & $94.3(4.9)$ & $92.6(6.1)$ & $97.9(5.4)$ & $98.6(8.7)$ & $92.3(12.8)$ \\
\hline & 3 & $62.9(3.8)$ & $79.4(4.8)$ & $82.3(5.9)$ & $82.6(2.2)$ & $92.8(6.6)$ & $99.6(5.8)$ & $99.6(4.5)$ & $101.4(1.8)$ & $108.3(5.7)$ & $108.5(12.5)$ & $107.6(2.5)$ & $120.8(5.8)$ & $116.6(5.7)$ & $127.7(7.6)$ & $131.1(10.0)$ & $119.2(19.3)$ \\
\hline & 4 & $71.8(4.3)$ & $92.3(4.9)$ & $95.3(6.7)$ & $96.4(3.6)$ & $107.2(7.1)$ & $116.0(6.5)$ & $114.3(3.4)$ & $117.5(2.4)$ & 125.8 (7.2) & $125.5(12.9)$ & $127.7(5.7)$ & $139.2(6.2)$ & $134.9(6.9)$ & $152.5(12.4)$ & $157.1(14.5)$ & 137.9 (26.5) \\
\hline & 5 & $77.2(5.4)$ & $99.4(5.8)$ & $104.7(6.9)$ & $105.3(3.4)$ & $116.6(7.5)$ & $128.0(6.6)$ & $121.5(9.2)$ & $128.9(2.1)$ & $137.5(6.8)$ & 136.8 & $142.4(7.9)$ & $151.2(5.7)$ & $147.6(8.5)$ & 169.5 (13.4) & $171.8(15.3)$ & $152.3(31.0)$ \\
\hline & 6 & $80.7(6.0)$ & $103.5(7.1)$ & $111.1(8.0)$ & $114.4(2.1)$ & 124.0 & $135.6(6.9)$ & $131.8(1.6)$ & $137.1(2.6)$ & $146.2(7.3)$ & $144.8(11.1)$ & $150.8(8.0)$ & $158.4(5.0)$ & $156.0(8.8)$ & $180.2(16.8)$ & $182.6(16.9)$ & $161.3(36.3)$ \\
\hline & 7 & $81.9(6.7)$ & $99.1(6.8)$ & $113.8(7.0)$ & $120.6(3.6)$ & $128.2(8.2)$ & $138.8(11.0)$ & $135.5(2.1)$ & $143.4(2.9)$ & 151.5 (7.3) & $151.1(9.6)$ & $157.5(7.7)$ & $163.9(5.0)$ & $163.9(11.3)$ & 176.0 (21.5) & 188.8 (15.9) & 169.6 (36.5) \\
\hline & 8 & $80.3(6.5)$ & $94.4(10.7)$ & $107.8(5.6)$ & $116.5(7.6)$ & $128.5(10.0)$ & $132.4(18.6)$ & $129.7(6.8)$ & 139.7 (13.6) & $138.2(5.3)$ & $148.8(11.5)$ & $159.2(4.8)$ & $154.3(7.1)$ & $163.6(9.9)$ & $168.2(37.4)$ & $188.2(13.3)$ & 171.7 (31.9) \\
\hline & 9 & $75.3(6.4)$ & $80.6(12.9)$ & 97.4 (14.2) & $107.2(12.7)$ & $118.3(7.4)$ & $119.0(22.2)$ & $118.3(11.2)$ & $119.4(16.8)$ & $116.5(5.5)$ & $135.0(15.6)$ & $151.4(2.2)$ & $136.9(19.9)$ & $155.0(7.7)$ & $150.3(51.1)$ & $179.5(10.7)$ & $163.1(26.9)$ \\
\hline & 10 & $66.4(5.0)$ & $53.2(13.0)$ & $78.3(23.7)$ & $89.3(18.4)$ & $98.4(6.5)$ & $94.1(23.3)$ & $97.8(13.2)$ & $88.8(21.9)$ & $84.7(5.7)$ & $109.8(16.5)$ & $132.5(3.1)$ & $109.8(28.5)$ & $129.6(6.6)$ & 115.6 (59.6) & $156.8(9.6)$ & $142.9(21.7)$ \\
\hline \multirow{9}{*}{ 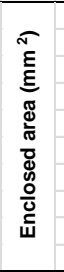 } & 2 & 969 (231) & $1508(274)$ & $1705(148)$ & 1838 (188) & $2532(476)$ & $2854(385)$ & $2630(231)$ & $3108(433)$ & 3314 (518) & 3099 (331) & 3655 (253) & 4196 (169) & $4068(714)$ & $5183(473)$ & $4948(497)$ & $4878(1024)$ \\
\hline & 3 & 1491 (322) & $2332(355)$ & $2725(165)$ & $2915(260)$ & 3834 (562) & $4323(495)$ & 4069 (203) & $4811(483)$ & $5138(736)$ & 4952 (472) & $5899(304)$ & $6360(124)$ & $6385(866)$ & $8118(1095)$ & 8036 (699) & 7789 (1746) \\
\hline & 4 & $1791(403)$ & $2843(419)$ & 3471 (197) & 3653 (342) & 4728 (649) & $5266(576)$ & 4944 (165) & 5945 (464) & 6223 (899) & $6104(678)$ & 7459 (399) & 7617 (230) & $7672(1146)$ & 10033 & $10061(706)$ & 9406 (2089) \\
\hline & 5 & $1929(433)$ & 3091 (341) & 3885 (189) & 3928 (449) & 5175 (712) & $5781(676)$ & $5152(862)$ & $6640(545)$ & $6818(1114)$ & 6926 (962) & $8269(409)$ & $8130(365)$ & 8370 (1218) & 11385 (1986) & 11053 (934) & $10335(2340)$ \\
\hline & 6 & $1897(428)$ & $3150(222)$ & $3958(212)$ & $4053(456)$ & 5325 (772) & 6039 (694) & $5573(202)$ & $6716(687)$ & $6964(1190)$ & 7033 (1014) & $8464(167)$ & 8095 (558) & $8433(1124)$ & $11467(2504)$ & $11052(827)$ & 10395 (2464) \\
\hline & 7 & 1779 (424) & 2681 (393) & $3758(203)$ & $3922(439)$ & 5087 (761) & $5558(886)$ & 5334 (138) & 6455 (766) & $6536(1196)$ & 6726 (1045) & 7984 (186) & 7852 (327) & 7851 (985) & 9899 (3857) & $10363(863)$ & 10119 \\
\hline & 8 & $1572(422)$ & $2163(552)$ & $3138(480)$ & $3423(608)$ & 4570 (702) & $4583(1200)$ & $4400(550)$ & 5412 (1245) & 4975 (759) & 5800 (922) & $7247(207)$ & $6412(971)$ & $6973(740)$ & 8281 (4529) & 9279 (889) & 9354 (2119) \\
\hline & 9 & $1292(362)$ & $1493(614)$ & $2459(818)$ & $2761(779)$ & $3626(300)$ & 3513 (1339) & $3437(809)$ & $3630(1126)$ & 3306 (426) & $4699(977)$ & $6203(437)$ & 4934 (1632) & $5778(640)$ & 6788 (4974) & 7797 (716) & $8043(1614)$ \\
\hline & 10 & $902(233)$ & $469(278)$ & $1482(962)$ & $1777(829)$ & $2221(342)$ & $1958(1080)$ & $2146(721)$ & 1751 (912) & $1449(207)$ & $2762(796)$ & $4394(371)$ & 3021 (1536) & $3669(445)$ & 4050 (3792) & 5590 (426) & 5725 (976) \\
\hline \multirow{10}{*}{$\tilde{z}_{2}$} & 1 & $14.3(2.2)$ & $18.1(2.0)$ & $18.3(0.9)$ & $20.1(0.8)$ & $26.3(5.0)$ & $24.1(1.9)$ & $24.1(0.8)$ & $27.3(4.1)$ & $28.5(3.6)$ & $27.1(1.9)$ & $28.0(3.4)$ & $30.6(2.2)$ & $28.6(3.8)$ & $33.2(1.7)$ & $32.3(2.6)$ & $34.2(2.7)$ \\
\hline & 2 & $24.5(3.1)$ & $30.3(3.9)$ & $32.8(0.8)$ & $35.0(2.4)$ & $42.6(4.8)$ & $45.6(2.9)$ & $41.7(1.2)$ & $47.2(4.1)$ & 49.0 (4.7) & $44.8(4.1)$ & $51.6(1.8)$ & $54.4(2.5)$ & $53.2(5.6)$ & $63.6(4.5)$ & $59.7(2.5)$ & $61.8(6.1)$ \\
\hline & 3 & $28.9(3.7)$ & $36.4(3.1)$ & $40.8(0.6)$ & $42.7(2.2)$ & $50.3(4.8)$ & $53.7(3.6)$ & $50.0(0.5)$ & $56.9(3.1)$ & $57.6(5.2)$ & $55.6(5.5)$ & $64.3(1.9)$ & $64.0(1.9)$ & $65.5(5.9)$ & $76.2(6.7)$ & $72.9(2.8)$ & $74.9(7.4)$ \\
\hline & 4 & $30.6(4.1)$ & $38.9(3.1)$ & $45.3(0.6)$ & $46.6(2.4)$ & $54.6(4.5)$ & $57.2(3.9)$ & $54.1(0.9)$ & $61.6(3.2)$ & $61.2(5.5)$ & $60.2(6.2)$ & $70.0(0.9)$ & $67.7(2.0)$ & $69.2(6.7)$ & $80.7(8.6)$ & $78.7(2.7)$ & $79.8(7.0)$ \\
\hline & 5 & $31.0(4.3)$ & 39.9 (2.2) & $46.8(1.2)$ & $46.6(3.6)$ & $55.6(4.6)$ & $57.8(4.2)$ & $54.0(4.5)$ & $63.4(3.6)$ & $61.8(6.4)$ & $62.7(6.7)$ & $71.0(0.9)$ & $67.5(2.5)$ & $70.2(5.9)$ & 83.1 (9.2) & $79.9(3.9)$ & $80.6(6.7)$ \\
\hline & 6 & $29.9(4.4)$ & $39.7(1.4)$ & $45.9(1.1)$ & $45.8(3.3)$ & $54.9(4.5)$ & $57.5(3.8)$ & $54.5(1.7)$ & $62.1(4.4)$ & $60.6(6.7)$ & $61.6(6.9)$ & $70.1(1.2)$ & $65.5(3.9)$ & $68.8(5.2)$ & $80.1(10.9)$ & $77.4(4.1)$ & $78.5(6.6)$ \\
\hline & 7 & $28.2(4.4)$ & 36.1 (3.5) & $43.7(1.4)$ & $43.5(3.2)$ & $52.1(4.5)$ & $53.1(4.5)$ & $52.0(1.1)$ & $58.8(4.8)$ & $56.5(6.5)$ & $58.1(6.5)$ & $65.6(2.5)$ & $62.5(3.1)$ & $63.6(4.1)$ & $71.3(16.4)$ & $72.7(4.3)$ & $75.3(5.5)$ \\
\hline & 8 & $26.0(4.6)$ & $31.1(4.9)$ & $39.4(3.7)$ & $39.8(4.4)$ & $47.8(3.5)$ & $46.7(6.5)$ & $46.3(3.7)$ & $52.0(6.8)$ & $48.7(4.5)$ & $52.0(5.4)$ & $60.8(2.3)$ & $55.3(6.2)$ & $58.4(3.4)$ & $62.0(20.7)$ & $67.0(4.1)$ & $70.4(5.4)$ \\
\hline & 9 & $22.8(4.2)$ & $24.6(6.3)$ & $33.7(6.8)$ & $34.9(5.9)$ & $41.8(1.6)$ & $39.1(8.7)$ & $39.8(6.1)$ & $40.7(7.7)$ & $39.3(2.9)$ & $46.3(4.6)$ & $54.7(3.4)$ & $47.7(9.7)$ & $51.3(3.5)$ & $51.9(27.3)$ & $60.0(3.7)$ & $64.6(3.8)$ \\
\hline & 10 & $18.3(3.0)$ & $11.5(5.2)$ & $23.3(10.9)$ & $26.5(7.8)$ & $31.3(3.2)$ & $27.0(9.3)$ & $29.9(6.3)$ & $25.7(9.7)$ & $24.2(1.9)$ & $33.9(5.1)$ & $44.7(3.2)$ & $34.4(12.6)$ & $39.1(2.5)$ & 36.8 (25.3) & $48.9(2.6)$ & $53.2(2.3)$ \\
\hline & 1 & $19.6(3.1)$ & $23.5(10.9)$ & $32.3(4.9)$ & $46.0(6.1)$ & $33.4(1.6)$ & $27.2(8.2)$ & $33.2(6.5)$ & $31.3(6.4)$ & $32.4(4.9)$ & $40.5(7.3)$ & $26.2(11.4)$ & $25.9(8.7)$ & $30.0(6.6)$ & $28.9(4.6)$ & 28.4 (14.3) & $31.6(9.5)$ \\
\hline & 2 & $14.3(5.2)$ & $19.7(10.5)$ & $23.1(4.0)$ & $35.8(5.4)$ & $27.8(1.4)$ & $22.7(4.6)$ & $27.6(4.6)$ & $24.4(5.8)$ & $29.2(6.5)$ & $34.7(7.7)$ & $18.3(10.1)$ & $19.8(7.1)$ & 24.8 & $23.4(5.2)$ & $21.2(12.2)$ & $24.2(9.0)$ \\
\hline 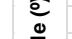 & 3 & $13.5(6.4)$ & $19.4(10.7)$ & $21.3(4.9)$ & $33.5(7.0)$ & $25.1(1.7)$ & $23.3(4.0)$ & $27.3(4.4)$ & $22.9(5.1)$ & $28.6(7.8)$ & 32.3 & $16.9(5.7)$ & $19.5(6.6)$ & 24. & $24.7(6.0)$ & & $23.7(9.9)$ \\
\hline & 4 & $15.1(6.3)$ & $21.1(9.5)$ & $21.2(4.9)$ & $32.4(8.5)$ & $24.5(2.3)$ & $24.1(4.2)$ & $28.7(3.7)$ & $23.6(4.6)$ & $29.2(7.1)$ & $31.8(9.6)$ & $17.7(3.4)$ & $20.2(6.4)$ & 26.5 & $27.8(6.0)$ & $23.1(9.1)$ & $24.3(9.5)$ \\
\hline & 5 & $19.2(6.2)$ & $23.9(8.6)$ & $22.5(4.4)$ & $32.8(10.7)$ & $25.4(2.2)$ & $25.6(4.3)$ & $30.9(3.7)$ & $25.5(4.3)$ & $30.9(6.7)$ & $32.8(8.8)$ & $19.9(2.5)$ & $22.0(6.5)$ & $29.0(5.1)$ & $29.8(5.2)$ & $25.6(7.9)$ & $25.1(9.4)$ \\
\hline & 6 & $24.5(6.0)$ & $26.4(8.1)$ & $24.4(3.1)$ & 35.1 (11.9) & $27.6(2.5)$ & $27.9(4.6)$ & $34.5(2.3)$ & $27.5(3.7)$ & $33.0(6.2)$ & $33.7(7.3)$ & $22.1(2.1)$ & $25.2(4.7)$ & $32.0(6.2)$ & $31.3(4.8)$ & $29.6(7.5)$ & $27.5(8.8)$ \\
\hline & 7 & $31.6(7.3)$ & $27.9(6.9)$ & $26.6(2.3)$ & 37.1 (11.7) & $29.9(2.8)$ & $30.3(4.3)$ & $37.4(2.5)$ & $30.1(2.9)$ & $35.8(6.2)$ & $36.5(5.7)$ & $24.9(2.7)$ & 29.6 (3.4) & $34.7(7.2)$ & $31.2(5.8)$ & $33.6(6.5)$ & $30.1(8.8)$ \\
\hline & 2 & $9.5(6.5)$ & $11.3(4.9)$ & $15.9(2.9)$ & $16.2(4.7)$ & $16.5(6.1)$ & $21.9(4.2)$ & $15.3(9.3)$ & $10.8(8.9)$ & $4.6(2.6)$ & $9.0(9.1)$ & $12.2(4.7)$ & $5.0(2.6)$ & $5.1(3.7)$ & $10.1(5.5)$ & $13.0(8.4)$ & $12.7(12.0)$ \\
\hline of & 3 & $6.3(4.5)$ & $9.7(4.0)$ & $10.8(7.0)$ & $10.5(3.5)$ & $11.3(5.1)$ & $18.2(4.1)$ & $11.1(7.0)$ & $9.9(6.2)$ & $5.6(4.2)$ & $9.0(7.7)$ & $11.7(1.9)$ & $4.6(2.2)$ & $5.5(3.9)$ & $7.0(5.9)$ & $11.9(6.8)$ & $11.5(9.6)$ \\
\hline & 4 & $4.6(3.9)$ & $9.1(5.0)$ & $9.2(7.9)$ & $8.6(5.8)$ & $9.5(4.9)$ & $14.6(5.5)$ & $9.1(4.1)$ & $8.8(4.3)$ & $5.0(4.4)$ & $9.6(6.6)$ & $11.8(1.9)$ & $4.4(3.1)$ & $6.8(3.9)$ & $6.2(5.7)$ & $12.5(6.8)$ & $10.6(7.2)$ \\
\hline & 5 & $5.4(3.7)$ & $10.2(4.8)$ & $9.4(7.0)$ & $8.1(2.5)$ & 7) & $11.7(6.0)$ & 6. & 7.0 & $4.5(4.4)$ & 8.0 & $10.7(2.5)$ & $5.2(3.2)$ & 8.0 & $8.4(5.9)$ & $12.9(7.6)$ & 8.4 \\
\hline & 6 & $7.1(4.0)$ & $10.9(3.5)$ & $9.2(4.4)$ & $5.5(5.6)$ & $8.0(5.2)$ & $10.7(7.0)$ & $7.5(4.7)$ & $5.7(3.0)$ & $5.2(3.6)$ & $6.8(5.0)$ & $9.8(3.6)$ & $6.3(4.7)$ & $9.0(6.2)$ & $9.3(7.5)$ & $13.4(7.1)$ & $6.8(4.9)$ \\
\hline 嵒 & 7 & $9.4(4.7)$ & $11.6(4.3)$ & $8.1(2.7)$ & $4.2(6.3)$ & $7.6(6.1)$ & $10.6(6.7)$ & $7.9(5.3)$ & $3.3(1.6)$ & $6.9(2.6)$ & $5.2(3.7)$ & $8.3(5.2)$ & $7.4(5.2)$ & $9.0(6.8)$ & $9.7(9.9)$ & $12.7(6.0)$ & $5.3(5.2)$ \\
\hline & 8 & $5.6(4.3)$ & $15.8(6.1)$ & $11.2(3.1)$ & $3.7(2.0)$ & $8.4(6.7)$ & $11.5(6.8)$ & $7.6(6.2)$ & $6.5(3.0)$ & $9.4(6.2)$ & $7.7(5.0)$ & $8.0(5.8)$ & $6.6(4.7)$ & $10.6(6.4)$ & $11.9(13.6)$ & $10.8(7.8)$ & $5.4(3.7)$ \\
\hline & 9 & $7.7(3.8)$ & $23.4(6.3)$ & $17.9(4.0)$ & $12.6(4.1)$ & $14.5(7.5)$ & $17.9(9.4)$ & $13.0(8.6)$ & $16.8(3.7)$ & $17.4(8.0)$ & $15.6(5.9)$ & $11.2(8.0)$ & $10.7(8.1)$ & $12.0(10.5)$ & 21.0 (11.5) & $16.0(7.3)$ & $9.8(5.8)$ \\
\hline & 10 & $18.8(4.2)$ & $28.8(2.7)$ & $25.2(2.8)$ & $23.2(4.3)$ & $24.5(6.3)$ & $27.8(8.6)$ & $26.4(7.6)$ & $26.3(2.2)$ & $26.0(6.2)$ & $28.1(3.8)$ & $21.3(7.2)$ & $21.1(7.6)$ & $25.0(6.8)$ & $31.9(7.9)$ & $27.3(6.3)$ & $22.9(3.0)$ \\
\hline
\end{tabular}

